\title{
Gendered harassment in secondary schools: understanding teachers' (non) interventions
}

Elizabeth J. Meyer

\begin{abstract}
This article provides an analysis of teachers' perceptions of and responses to gendered harassment in Canadian secondary schools based on in-depth interviews with six teachers in one urban school district. Gendered harassment includes any behaviour that polices and reinforces traditional heterosexual gender norms such as (hetero)sexual harassment, homophobic harassment, and harassment for gender non-conformity. This study shows that educators experience a combination of external and internal influences that act as either barriers or motivators for intervention. Some of the external barriers include: lack of institutional support from administrators; lack of formal education on the issue; inconsistent response from colleagues; fear of parent backlash; and negative community response. By gaining a better understanding of the complex factors that shape how teachers view and respond to gendered harassment, we can work towards more effective solutions to reduce these behaviours in schools.
\end{abstract}

\section{Introduction}

The problem of sexual and homophobic harassment in schools has been the subject of scholarly investigation since the early 1990s, when two concurrent bodies of research emerged that began examining the phenomena of sexual harassment (Stein 1992; Corbett, Gentry, and Pearson 1993; Louis Harris and Associates 1993; Larkin 1994; Roscoe 1994) and homophobic harassment in schools (Sears 1991; Friend 1993; Louis Harris and Associates 1993; The Governor's Commission on Gay and Lesbian Youth 1993; O'Conor 1995; Reis 1995). More recently, the gendered and sexualised aspects of some bullying behaviours has been explored in both quantitative and qualitative studies (Martino 1995; Stein 1995; Epstein and Johnson 1998; Duncan 1999; Renold 2000; California Safe Schools Coalition 2004; Chambers, van Loon, and Tincknell 2004; GLSEN and Harris Interactive 2005; Wilson, Griffin, and Wren 2005). These studies have shown that sexual and homophobic harassment are accepted parts of school culture where faculty and staff rarely or never intervene to stop this harassment. Students report that teachers stand by and allow biased and hurtful behaviours to go unchallenged. Why teachers do not intervene consistently is the central question for the research presented in this article. Six secondary school teachers in one urban public school district in Canada were interviewed to understand the phenomenon from their point of view.

This article will start by defining gendered harassment and the behaviours that are examined together under this term. This is followed by a description of the methods used for data collection and analysis. The third section presents the findings of this study which indicate that there are external and internal influences that shape how teachers respond to gendered harassment in their schools. The external influences are divided into institutional (formal) and social (informal) factors which interact with teachers' internal influences to shape their experience of their school culture. The interaction of these three influences is explained with specific regard to how it shapes teachers' perceptions of and responses to student behaviours. After presenting a diagram that summarises the barriers and motivators that shape how teachers respond to gendered harassment in school, I will conclude with a discussion of how the use of this model can assist educators working to create more inclusive school climates.

\section{What is gendered harassment?}

Gendered harassment is defined as any behaviour, verbal, physical, or psychological, that polices the boundaries of traditional heterosexual gender norms and includes (hetero)sexual harassment, homophobic harassment, and harassment for gender non-conformity. Common examples of such behaviours include name-calling, jokes and gestures, as well as physical and sexual assaults that are sexist, homophobic or transphobic in nature (Meyer 2006). The focus of this article is on gendered harassment because research reports indicate that teachers are less likely to intervene in cases of sexual, homophobic and transphobic harassment than in 
other forms of bullying and harassment in schools (Harris Interactive 2001; California Safe Schools Coalition 2004; Kosciw and Diaz 2006).

These behaviours are all linked to the public performance and norm-setting of heterosexual gender roles. It is important to clarify that although these forms of harassment are linked, the categories of harassment in regard to sex, sexual orientation and gender expression must be understood separately in order to help educators develop a deeper and more complex understanding of these practices in schools.

Queer theorists and other scholars of gender and sexuality have argued effectively that sex, gender and sexual orientation are three distinct aspects of an individual's identity and experience (Butler 1990; Sedgwick 1990/1993; Bem 1993; Connell 1995; Jagose 1996; Sullivan 2003). I share the perspectives advanced by these theorists that it is the hegemony of heteronormative patriarchy that constructs dominant notions of sex, gender and sexual orientation in very oppressive ways. It is this social construction of opposing binaries (i.e. male/female or gay/straight) (Butler 1990; Bem 1993) combined with the dominance of hegemonic (heterosexual) masculinity (Connell 1995; Mills 2001) that is at the root of gendered harassment. The fact that many individuals conflate these ideas often results in forms of sexual harassment, homophobic harassment and harassment for gender nonconformity. Such conflation can result in gender non-conforming individuals being attacked with anti-gay language (such as a men who are artistic being called 'faggot'; or athletic, short-haired women being called 'dyke'), and gay men and lesbians being sexually harassed (gay men due to their perceived femininity; or lesbians because women are viewed primarily as objects of male desire). To clarify what constitutes gendered harassment, definitions of each of the three forms - sexual, homophobic, and gender nonconformity - are provided below.

The legal definition for sexual harassment includes two different forms: quid pro quo and hostile environment sexual harassment (Lee et al. 1996, 384). This study focuses exclusively on forms of hostile environment sexual harassment, as no incidents of quid pro quo were mentioned by participants. Such forms of sexual harassment appear to be much more prevalent, and have been defined as 'unwelcome behaviour that can include both physical or verbal conduct and that has a sexual or gender component' (Reed 1996, 21). I also include non-verbal, or psychological, behaviours such as gestures, facial expressions and relational behaviours such as social exclusion in this definition.

Homophobic harassment, the second form, is defined as unwelcome behaviours that can include physical, verbal and non-verbal conduct that denigrate people who are, or are perceived to be, gay, lesbian, bisexual or queer. As most of these behaviours have a sexual or gender component, it is often a subset of sexual harassment behaviours. Anti-gay epithets are commonly used as insults in schools. These may be used with no actual connection to one's sexual orientation. As many scholars of masculinity have argued, these terms are often used because they are seen as the worst thing you can call a boy (Smith and Smith 1998; Kehler, Davison, and Frank 2005; Mac an Ghaill 1995; Martino 1995; Robinson 2005). It calls into question one's masculinity by challenging one's sexual orientation. Girls are also subject to this harassment if they are perceived to be too 'masculine' or do not show sexual interest in their male peers (Wood 1987; Louis Harris and Associates 1993; California Safe Schools Coalition 2004; Duncan 2004; Kosciw and Diaz 2006).

Many victims of homophobic harassment are also targeted due to their gender expression. This is the third form of harassment: harassment for gender non-conformity (also known as transphobic harassment). Individuals whose bodies and identities transgress dominant notions of masculinity or femininity and disrupt the dominant paradigm of a gender binary are the main targets. Recently a few studies on homophobia in schools have addressed this link (Bochenek and Brown 2001; Mills 2001; California Safe Schools Coalition 2004; Wilson, Griffin, and Wren 2005; Poteat, Eads, and Kimmel 2006), but further investigation in this area is needed. In order to clarify how bullying, harassment and forms of gendered harassment are related, I designed the diagram shown in Figure 1 that shows how these concepts intersect and how they relate to other forms of bullying and biased harassment.

The ways that teachers understand and perceive these forms of gendered harassment will impact how and when they choose to intervene in incidents that they witness at school. 
It is important to explore the teachers' perspectives in order to understand the barriers and motivators that shape how and when they choose to intervene. By identifying the barriers from the teachers' perspectives, we can design more effective intervention programmes to

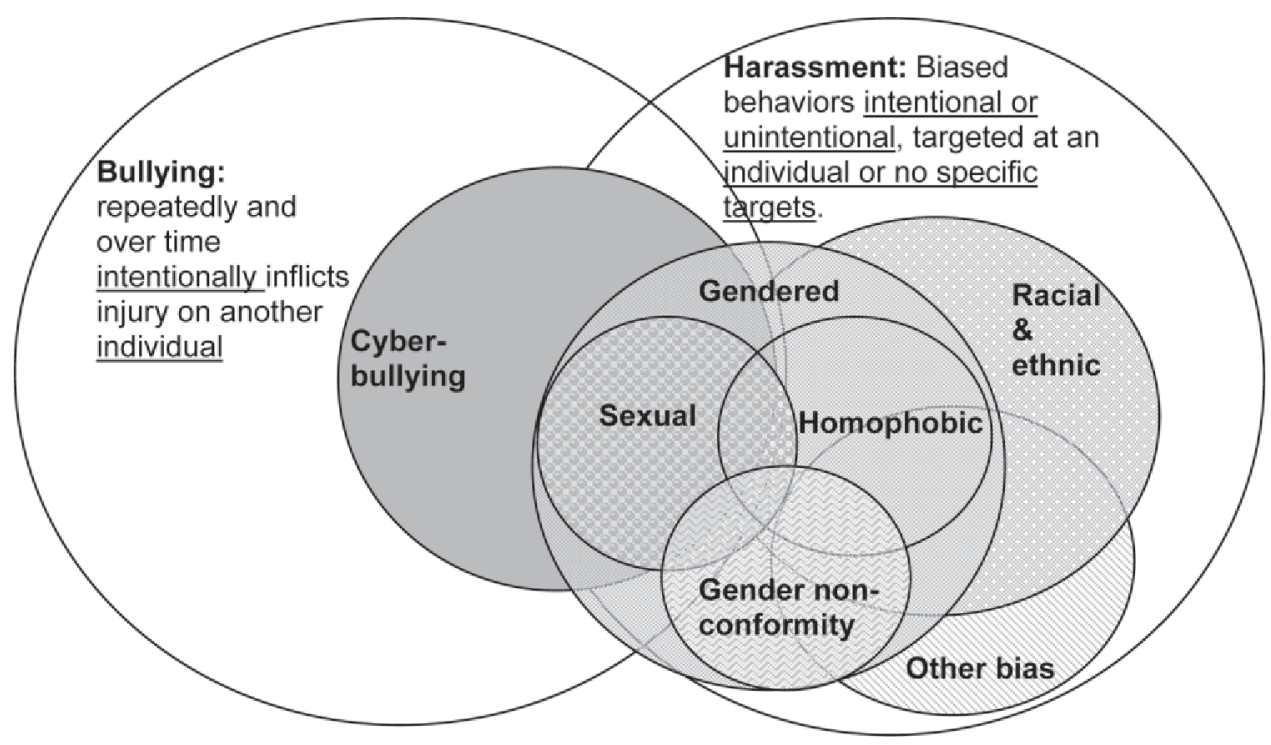

Figure 1. Bullying, harassment, and gendered harassment.

support educators in their efforts to create safer spaces in schools. The next section presents the methods used to gather data for this study and the demographics of the participants.

\section{Methods}

This study is based on in-depth interviews with six Canadian teachers working in secondary schools in one urban public school board (Van Manen 1997; Patton 2002). Participants were recruited using both snowball and maximum variation sampling methods (Maykut and Morehouse 1994) to ensure a broad range of experiences and perspectives. I was able to gain a diverse group of teachers for this study with a relatively small group of participants. The demographics of the participants are presented in Table 1. The information is presented in this format in order to protect the identities of the participants. It is important to note that of the teachers who volunteered to participate in this study, none identified as EuroCanadian heterosexual males. The impacts of this self-selection on the study will be discussed in the findings.

Through a series of three open-ended interviews (Seidman 1998), teachers described how they perceived and responded to incidences of gendered harassment in the context of their individual experiences in their current school culture. The first interview focused on the teacher's career path, philosophy, and roles in the classroom, then discussed the general issue of bullying. The concept of biased harassment was introduced in this first interview by discussing issues of race and ethnicity in their schools. The second interview focused on the three types of gendered harassment and addressed them in the following order: sexual harassment, homophobic harassment, and harassment for gender non-conformity. The third interview allowed teachers to reflect on the discussions of the first two and draw connections and explore their (in)actions in their current school contexts. These interviews were tape-recorded and transcribed for analysis. Data analysis was conducted in an ongoing and exploratory design as this research seeks to uncover common themes between teachers' experiences that will help inform future studies and school interventions (Maykut and 
Table 1. Participant demographics.

\begin{tabular}{lll}
\hline Gender & 3 men & 3 women \\
Sexual orientation & 3 heterosexual & 3 gay or bisexual \\
Ethnicity & 3 Euro-Canadian & 1 Indian \\
& & 1 French-Canadian/Métis \\
Religion & 3 No affiliation & 1 Arab \\
& & 1 Christian \\
Languages & & 1 Muslim \\
& 1st (Native) & 1 Bahai \\
& 4 English & 2nd (Fluent) \\
Citizenship & 1 French & 3 French \\
Average years teaching & 1 Hindi & 2 English \\
& $3-1$ st generation Canadian & 1 Arabic \\
& 5.6 & $2-5$ th+ generation Canadian \\
Average age & & $1-2$ nd generation Canadian \\
& & $1-5$ years: 3 \\
& 31 & $5-10$ years: 2 \\
& & $10+$ years: 1
\end{tabular}

Morehouse 1994). The data were analyzed using both contextual and thematic codes which situated the teachers' identities and experiences within their school contexts and allowed common themes to emerge among their experiences.

\section{Findings}

In developing an understanding of how teachers perceive and respond to incidents of gendered harassment in secondary schools, a theoretical model emerged from the interview process. There are four elements in this model that demonstrate the relationship between the main factors that influence how teachers respond to gendered harassment in school: external influences, internal influences, perceptions and responses. The interaction of the external and internal influences shapes how a teacher perceives student behaviors and then decides to respond to them. A detailed description of the different external and internal influences is presented in the following sections to demonstrate how they influence perceptions and responses of teachers. These descriptions are supplemented with excerpts from the data to show how teachers talk about these factors and how they shape their practice.

\section{External influences}

Multiple outside forces exert influences over teachers' perceptions and behaviours in school. These external influences are described as the school culture, or the 'significant perceptions, thoughts, and beliefs held by individuals associated with the school' (Maehr and Buck 1993, 42). School culture is created by many factors that fall into two categories: institutional and social influences. In this section, I present the sub-themes in these categories to illustrate how teachers experienced their schools' cultures.

\section{Institutional influences}

The formal structures that impact how participants perceive their school culture include four main aspects of the organization, including: a) administrative structures and responses; b) provincial curriculum demands and teacher workloads; c) teacher education and training; and d) written policies. Through the course of the interviews it became clear that these formal aspects of the school interacted with the informal aspects of the school culture to shape teachers' experiences and interactions with their students. 
The first sub-theme in this category, administrative structures and responses, elicited discussion about not feeling supported by their administrators and believing that oftentimes the discipline meted out for instances of sexual or homophobic harassment was not sufficient:

If there's an incident in my classroom I have to seek out the administration to get the followup on it. You just have to get to know the system and know what the expectations are "cause they're stretched. They don't have any time ... I personally had a few issues during the year with discipline and the VP wasn't there, and the principal dealt with it, and I always felt the same, the he just wasn't firm enough. (FT03)

As far as discipline, how it's handled, I had to push for action when another kid called a kid 'faggot'. However, I know that in my school a racist comment was certainly not tolerated and it was dealt with immediately. (MT05)

These comments show a trend of teachers not trusting their administrators to support their actions and the feeling that they have to handle most non-violent discipline issues alone. They spoke quite consistently about their schools' strong and clear response to any kind of physical violence, but in terms of verbal harassment or other forms of psychological torment, they felt that the administration did not want to be bothered with these issues. This is important in light of the findings of other studies that have found that antisocial behaviour in students increases when administrative support is inconsistent and when there is an absence of follow-up from school leadership (DiGiulio 2001, 81).

The second theme brought up by all the teachers was the challenge they faced meeting the curricular and workload demands of their jobs. This was one of the most common obstacles that teachers talked about that prevented them from acting as consistently as they would like towards various forms of verbal harassment. Many teachers felt great pressure from their administration to cover the required amounts of curricular material and the stresses placed on them by large classes and demanding course loads caused them to ignore certain behaviours.

[I don't stop name-calling] if I'm too tired, if there are set things I need to get through in a lesson. I know my lesson is going to take 60 minutes, I've only got 70 minutes to deliver it, I've got 10 minutes to waste. Right now my job is being a teacher and I have to get through the math before the end of the year. It's not on my priority list. (MT01)

Sometimes as a teacher I just want to ignore it. There are times that I ignore it. I'm not perfect. There's so many times when I have TOO much to do, like we gotta get through this lesson. (FT03)

You're running all the time, you're pretty well tired constantly and you don't sit. You let stuff slide sometimes. (MT05)

These teachers are exhausted and overwhelmed with the professional demands placed on them and do not feel as if they are given the necessary support or resources to deal with everything that they are expected to address. They expressed frustration when talking about the limitations they felt, but very few of them offered any critique of the formal structures that caused them to feel overwhelmed. By only acting within the micro-structures of their classroom when dealing with behaviour issues rather than addressing the macro structures of the school, they are extremely limited in what they can do to improve student safety and school climate.

Education and training was the third theme. Most teachers felt that their teacher education programmes did not sufficiently prepare them to address incidents of harassment or bullying, particularly related to gender and sexual orientation. This reflects findings by other researchers in this field who have noted the lack of information in gay, lesbian, bisexual and transgender issues in education texts (Jennings and McGillivray 2007) as well as resistance to addressing issues related to sexuality and homophobia in teacher education programmes (Robinson and Ferfolja 2001). Additionally the teachers in this study did not feel that they had many opportunities to pursue additional training in this area since they were encouraged to do professional development primarily in their area of instruction. 
I've had no training [on how to address bullying] ... The educational degree was really worthless. I felt that we didn't really get that kind of necessary education. How to deal with certain issues like [bullying]. We were just told, 'avoid this and this' ... We're constantly being told how to protect ourselves. We're not constantly being told how to protect these young people from other young people. (MT06)

[I never got any] training in school [on] bullying. I do not think that we ever studied anything related to that ... I don't know if I was really attuned to [sexual harassment] - to be quite honest. Maybe that's why I wasn't so aware that it was going on because as a part of my training it had never really been brought up as an issue to be concerned with. (FT02)

Other teachers had taken their own initiative to pursue additional studies that had exposed them to issues of gender, sexual orientation, and race, and they spoke about the importance of these opportunities in improving their practice as teachers.

I'm not the average teacher or the average individual coming in on the issue. I received a lot of training on gender harassment and bullying and sexual orientation and identities, multiculturalism and racism. All of that was part of my training [as a student leader in university]. I have other personal issues that have challenged me through the past couple years that I've had to deal with, but in general I've got the artillery behind me if I want to use it. I was involved in giving workshops in a lot of these areas to the other student leadership groups ... I've done a lot in the area, compared to a lot of other people. (MT01)

The teachers who did get some education in this area are ones who took it upon themselves to seek out these opportunities. These decisions were shaped by their intrapersonal influences such as their personal identities and educational biography. A discussion of how these internal factors shape teachers' perceptions and responses in schools is included later in this article.

The final theme under institutional influences was that of written policies and how teachers' knowledge of their school's and school board's policies influenced how they addressed various forms of bullying and harassment. One teacher did voice a belief that his school's policy on bullying was clear, yet he spoke at other points in the interview about his frustration with colleagues for their lack of awareness of and attention to the issues of racism, sexism, and homophobia in his school (MT06). The rest of the participants did not share the belief that they had a clear understanding of their school's policies. The perceptions that teachers shared about their experiences with the formal structures of their schools present a clear description of some of the structural obstacles that exist and prevent educators from responding consistently and effectively to incidents of gendered harassment.

\section{Social influences}

It quickly became apparent that the informal structures of the school, or the social norms and values, exerted the most powerful influence over teachers' behaviours. The three most prevalent themes were: a) perceptions of administration; b) interpersonal relationships; and c) community values. These will be addressed in this order to explore how these factors impacted teachers' experiences in their schools.

The first area is teachers' perceptions of their school's administrators. Under this theme, participants spoke of issues such as leadership style, personal values, professional priorities, and policy implementation. The following excerpts demonstrate how the teachers perceived their administrators, and how these perceptions shaped their actions in the school.

Our administrator who dealt with disciplinary problems was a real jock and the real 'man's man' and he'd sit the boys down and say, 'what the hell do you think you're doing?' I think that he gave them the old football huddle, sit down and I'm gonna tell you how to act in the classroom. And I think that's as far as it went ... I feel that the administration didn't want to get involved because they were these [southern European ethnicity] men and, if they were to come into a staff meeting and say, 'we need to address some of the homophobic attitudes,' I could never hear them talking about something like that. So maybe that's part of the problem; even the administrators had that [southern European ethnicity] kind of mentality. (FT02) 
I always find that when I'm working with principals and vice principals that it's their own morals and their own beliefs that come through and if it's something that they don't really think's a big issue, then why are they going to be proactive about it? Or just the gender of the administrator, I think that plays into it as well. (FT03)

I think that our school puts bullying at the very top of the list because it's easy to deal with. Sexual assault, homosexuality, racism are much more controversial and they tend to feel like the less [the administrators] have to deal with it, the better off they are. (MT06)

These perceptions reported by teachers demonstrate how powerful an administrator's style is in shaping the culture of a school. Teachers get messages from their school leaders about what they personally value and what issues they feel are important to address. In the above statements, the teachers are talking about the lack of leadership in addressing sexual and homophobic harassment in their schools. By choosing not to address these issues, administrators teach their staff that these behaviours are not viewed as problematic, and reinforce the primacy of heterosexual masculinity in schools. Whether it be through official communications in staff meetings, or more typically through observed patterns of behaviour and advice from more experienced teachers, a principal's priorities and attitudes towards issues permeate the school and shape the culture.

Another area of administrative influence is that of policy implementation. The way administrators interpreted and applied various school-board and school-wide policies sent clear messages to teachers about how they should enforce and apply those policies. Some teachers felt there was a clear expectation communicated about bullying policies, whereas others believed that very little had been done to inform teachers about how certain policies should be interpreted and applied.

The kids are astute enough to see that when they use the word faggot they won't get sent to the office and when they use a racial slur, they get sent to the office. It's a very quick connection to make ... I had one kid call another a faggot. I hauled him to the principal; I asked for a suspension, the principal didn't want to suspend him. It was one of the vice-principals and they saw that I was about to blow my top so they suspended the kid. But I really had to push for it. (MT05)

In the two high schools I've been it really depends on your Vice Principal. They basically set up according to their beliefs. Their policies reflect a lot about them and how they deal with it. (FT03)

Any type of physical harassment would get a strong response. They just don't tolerate any type of fighting or anything in the school, so if that goes on, there's definitely a response to that. But in things where people are just kind of saying things to one another - no, those are not responded to in the same way. And it would be difficult to respond to them because they occur so much - it's almost like they're a part of the school culture. (FT02)

The lack of consistency or clear guidelines for responding to forms of gendered harassment left teachers feeling isolated and unsupported in their efforts to address incidents of nonphysical harassment. Conversely, participants reported that any act of physical violence, regardless of its motivation, was handled quickly and uniformly due to zero-tolerance policies regarding such behaviour in schools.

A second area that was discussed was the role of interpersonal relationships in shaping the school culture. Their personal relationships with administrators had a significant influence in how they perceived their ability to act in the school. Teachers in two of the three schools did not feel supported by their administrators.

Eventually I told [my Principal] that I was going to tell the kids [that I'm gay]. She said, 'if you come out to those kids I will not guarantee your safety at this school'. I had to make a decision at this point. She was tough. I couldn't stand working for her ... She didn't like me because I was gay. That was clear. (MT05) 
If there's bullying going on in your classroom, then you must be a bad teacher. You don't feel like you can go to [the administration] because it reflects badly upon you as a teacher, because it's like saying to them, 'I can't handle my classroom. I need your help.' ... You play the game because the principal decides what you're going to teach the following year and if he doesn't like you then he gives you the worst classes and five different subjects to teach and everybody knows it works that way. So if you don't get along with the principal and you don't kiss butt a little bit then you'll pay for it the next year. That's the power that they have. (FT02)

These reports show that these teachers didn't feel that their decisions and actions towards acts of gendered harassment would be supported by their administration. This professional tension created a strained relationship and made both of these teachers question their place at their schools.

The working and personal relationships with colleagues also had an impact on their experiences in their schools. The participants in this study spoke regularly about their struggles and alliances with other members of the school staff. They also complained about a lack of consistency in enforcing certain school rules and policies. Many felt that they could not defend taking certain actions against students if other teachers were not also addressing those same issues.

I spent the first couple months enforcing all of this [uniform policy, swearing, and name-calling] and there are some teachers that just never enforce it and so you realize that out of 20 teachers, we have about five who do all the enforcing and you just can't anymore. You can't do it ... I just feel like some teachers just don't really have a clue. It's scary. It's really scary. (FT03)

In my classroom I can deal with it and give my students a thousand detentions, but if they go into another classroom and they're allowed to bully then they'll come back into my classroom the next day and I'll be dealing with the exact same issues. (FT02)

[The prevalence of homophobia and lack of staff response] is a constant reminder that I'd like to work in a different community. (MT02)

This lack of consistency caused the teachers in this study to speak about the frustration caused by their colleagues. They spoke highly of a few, but generally did not feel a strong connection with their fellow teachers. Lack of consistency can also contribute to greater problems with behaviour in the school. Other researchers have found that inconsistent responses by the school result in inconsistent follow-through by staff, which often results in more behaviour problems (Mayer 1995 cited in DiGiulio 2001, 81). The influences of coworkers on teachers who are new to a school cannot be overstated. It is clear that new teachers have to learn the hidden curriculum and unwritten rules of each school they work in. Unfortunately, these codes of conduct that get taught in the staff room and through informal interactions oftentimes lead to teachers learning bad habits and accepting lower standards of professionalism than they would otherwise set for themselves. As one teacher stated, 'As the new teacher, I just do a lot of observing, and seeing what's acceptable and what's not, and how we deal with things here at that individual school' (FT03). Another teacher reported being reprimanded for arriving late to school when he didn't have a first period class, and his response to the principal was, 'tell the other older teachers to [be on time]. I'm doing it 'cause I see them' (MT06).

Teachers' interactions with and perceptions of their colleagues are also factors that shape how they will act in various situations. Participants in this study spoke of racist, sexist and homophobic comments from other staff and a lack of awareness of these issues from more experienced teachers. The stories that these teachers shared about the frustration they felt and the difficulties they faced due to colleagues who acted in irresponsible or oppressive ways were troubling. One female teacher spoke of students telling her about a fellow male teacher who was sexually harassing them. When she reported it to her department head, he informed her that he was aware of the situation; however, the teacher was never punished and continued to teach at that school (FT02). Several teachers told stories of hearing homophobic jokes and comments among the staff (FT03, FT04, MT01, MT05), as well as of 
being harassed themselves (MT01, MT05) and getting little or no support from their administration. It is not surprising to see how challenging it is to work against various forms of bias and harassment in students when professional educators and employees of the school are modeling the exact behaviours these teachers are trying to prevent.

Teachers' relationships with students also had an influence on their responses to various forms of bullying and harassment. The participants in this study spoke mostly of a high respect and a deep level of care for their students and their overall well-being. They worked very hard to have positive relationships with their students and often made themselves available during their own free time to provide homework assistance (FT02, MT01) and extracurricular supervision (MT01, FT03, MT06), and opened up their classrooms for students to hang out during lunch periods (FT02, FT04). For example, one teacher stated, 'some of them wanted support. They would come in to my classroom during lunch and talk ... there was one girl who had so many problems at home and she used to come in and talk to me. Why did she choose me? I think it's 'cause I took an interest in her life' (FT02). Another teacher spoke about helping out with a teacher-initiated breakfast programme: 'We gave breakfast to the kids. So many of our kids came in to the school hungry, so four of us teachers did shifts. I did it a couple days [per 8-day cycle]' (MT05). They felt that these extra efforts made them more approachable to students to report incidents of harassment, and allowed them to develop deeper connections with their students so they could provide them additional support and information. One teacher reflected on speaking to his students about homophobia, and said, 'With my community, I find that you need to be personal with them in order to get the response. If you don't make it personal, then you're just someone else giving them a piece of information' (MT01). A second teacher remarked, 'They spend more time with us than they do with their parents. I was their parent in many instances. I gave them structure; I spoke to them and showed them I cared for them' (MT05). Several teachers spoke of special relationships with certain students that had resulted from these extra efforts. It was clear that these connections were quite meaningful to the teacher and were most likely of significant positive impact to the students and their perceptions of their school community.

The last area of interpersonal relationships that shaped teachers' perceptions and responses is interactions with parents. This was not a prevalent theme through all teachers' experiences, but the teachers who did address the issue of parents indicated that it had an impact on how they felt they were able to work in the school community on addressing certain behaviours in the school. One teacher described being targeted by parents for homophobic harassment, 'I was getting called faggot and parents were calling, were coming onto the property to harass me while I was doing yard duty' (MT05). A second teacher reported frustrations with getting parental support for punishments:

There's a different culture now with parents not backing up the behavior, or a student that you're punishing for a certain word that they used in class and then the father comes into the school for a meeting and says, 'Well, what the $\mathrm{f}^{* *} \mathrm{k}$ are you doing suspending my son? To the Vice Principal ... in some ways, parents don't necessarily help with the solutions. (MT01).

These examples show that the participants feel that parents are often working against what they are trying to teach students. Whether it is modeling disrespectful behaviour towards teachers, targeting them for homophobic harassment, or challenging the school rules, these parental behaviours work against the possibility of reducing gendered harassment in school. It seems evident that the accumulation of these interactions with administrators, colleagues, students and parents conveys clear and consistent messages to teachers about which behaviours are tolerated in a school and which ones are not. These social norms do not emerge in a vacuum, but are often a reflection of the community in which the school resides. The third area of social influence is what the teachers called 'community values'.

Each of the three schools in this study were in the same school board, but were situated in very different communities. It was clear in the conversations with these teachers that the values and expectations of the community were significant factors that shaped what could and could not happen in their school. Their interpersonal relationships with colleagues and families are created in this context and are often actively transmitting the values of the broader school community. These, in turn, influenced the school culture. 
Teachers noted how external influences from students' families and out-of-school time played a role in shaping the climate and priorities of the school. In one school, the high expectations of families placed an extraordinary emphasis on students' grades and extracurricular involvements. One teacher pointed out, 'I think student performance in academics, community, cultural, sports activities are the top priorities of the way our school runs ... as long as the kids are doing well, the school goes on and we can justify our position in the public school system ... Here there's a perception that it's perfect when it really isn't. We've got good kids, but they have lots of problems too' (FT04). In another school, the cultural values of one dominant European ethno-cultural group heavily shaped students', teachers', and administrators' behaviours. One teacher described her students in the following way: 'With my [European ethnicity] students, the boys had such big egos, and they thought the they should be waited on basically by their teachers, by their fellow girl students, they thought that they were really, really important and they were obviously led to believe that by their families' (FT03). In the third, the harsh realities of poverty, violence, and racism were prevalent and permeated all aspects of the school. One participant described this school by saying, 'Many of our students came from single family homes and homes that were certainly socio-economically disadvantaged. A lot of kids had jobs at night and their main focus wasn't always school. I think a lot of our kids didn't come from safe places. Their homes weren't safe, they weren't fed' (MT05). Although all of these schools had very different cultures and social realities, the participants' spoke of very similar obstacles to addressing forms of gendered harassment.

As other scholars have found, school culture is much more likely to determine and support what it is that students, teachers, and others say and do than is the formal management system. This means that teachers are more inclined to act in ways that reflect shared norms and values of other teachers than in ways defined by school policy (Stader and Thomas 2006, 16). The way teachers choose to navigate the culture of their school is shaped by several internal factors that they spoke of in their interviews. The next section offers an explanation of these influences.

\section{Internal influences}

Each individual brought a specific set of identities and experiences to his/her teaching as well as the research process. What quickly became evident in the interviews was the significant influence of their personal identities and their own experiences in school (educational biography) on shaping how they perceived and acted in the culture of their current school. All of the participants talked about their experiences of having felt marginalized in society due to their identities as gay, bisexual, women, or people of colour. These experiences in their own schooling and professional life acted as very strong motivators to act out against discriminatory behaviour that they witnessed as teachers. At times, these factors also acted as barriers to consistent intervention because they felt vulnerable as minorities in their schools. This vulnerability and the tensions it caused for the teachers was a major source of struggle for the participants. They cared deeply about reducing the harms of homophobia and sexism and other forms of bias for their students, but also had to negotiate how they experienced these forces as teachers. Selected excerpts from the teachers' narratives are presented below to highlight the aspects of their internal influences that impacted how they responded to incidents of gendered harassment.

\footnotetext{
Steve Pyre ${ }^{1}$

You are a role model.

Am I more vigilant because I'm gay?

Probably, but it's the right thing to do.

I'm willing to deal with the backlash.

Jessica Crosby

I was interested in social change.

I felt like an outsider. I was a woman.

You worry until your job is secure.
} 


\section{Anita Day}

It's tough as a teacher of colour. I have very little room to slip up.

Is that really about race? Yeah, maybe.

You get desensitized.

I consciously make an effort to get at my own prejudice.

My dad was outright discriminated against.

\section{Pierre LeSage}

I got called fag. I'm more sensitive. I was always afraid.

Being a gay man, having experienced harassment, made me define my role as a teacher.

\section{Homer}

I want students to feel welcome.

We were the only minority group, I got incredibly bullied.

I catch myself saying, 'oh that's so gay'.

I'm conscious of what I'm doing. I'm trying to correct myself.

\section{Sam Kaye}

Be a role model. Have my students be in a safe spot for a change.

When you yourself are gay, you're even more scared.

I'm so sensitive. It pertains to me.

The connection of personal experiences with discrimination has proved to be a motivating factor in other studies as well. In a study of eleven educators in the southern United States, Jones concluded that victimisation emerged as a significant impetus for educator activism and intervention regarding sexual harassment in their schools $(2005,26)$. This is an interesting finding as there was not a single volunteer in this study who identified as a white, heterosexual male in spite of repeated attempts to locate one. This is not meant to imply that there are not white straight male allies who are engaged in this work, only that they were more difficult to recruit than I had anticipated. They can be important partners in such transformation efforts in schools and should not be overlooked. As several teachers pointed out, it is their personal experiences with discrimination and marginalisation that made them particularly sensitive to these issues in schools. The challenge that this finding presents is how to raise the awareness of educators who have not personally felt the impacts of discrimination or exclusion from dominant culture.

\section{Conclusion}

What became clear through the course of the three interviews was that these teachers did not feel that they could put a stop to gendered harassment in their schools. The presence of so many external barriers challenged their ability and eventually even their willingness to consistently interrupt sexist, homophobic and transphobic language and behaviours. A similar study in the United Kingdom concluded that the prevailing rhetoric of liberal individualism acted as a barrier to teachers' responding to misogynistic bullying by obscuring 'structurally reproduced relations of gender domination' (Chambers, van Loon, and Tincknell 2004). As other researchers have pointed out, sexual and homophobic harassment have been normalized as aspects of everyday school culture and are often not questioned or approached by educators from a critical or feminist perspective (Larkin 1994; Hepburn 1997; Chambers, Tincknell, and Van Loon 2004).

The interaction between the external influences and internal influences can explain the wide variety of perceptions of and responses to gendered harassment by secondary school teachers as well as the inconsistencies reported by students in other research. As Figure 2 illustrates, external influences are filtered through each teacher's internal influences, like water poured through a coffee filter. As the data has shown, both external and internal influences present barriers (in grey) and motivators (in white) to teachers' interventions. These influences vary on the basis of teachers' identities and experiences in their school cultures, but in all cases in this study, the barriers outweigh the motivators for intervention. It is as if teachers' eyes are covered by institutional and social barriers that tell them not to see gendered harassment and not to intervene. However, their internal motivators often encourage them to see and to act in 
spite of these strong external barriers. This imbalance creates a constant struggle for the teachers who are trying to reduce such behaviour in their classrooms and schools. There is insufficient room here to elaborate on specific recommendations for transforming school cultures which have been addressed in depth elsewhere (Meyer 2006, 2008).

Most teachers in this study spoke of their personal desire or commitment to challenge issues of gendered harassment but felt limited in their actions due to a perceived lack of support from the administration and their colleagues. They felt isolated in addressing the problem of homophobic name-calling in particular, and felt that it was too prevalent an issue in their school for them to tackle alone. The lack of intervention by colleagues and the lack of demonstrated support from the administration resulted in many of these teachers giving up and limiting their interventions to only the most severe offenses. The lack of consistency in reporting and responding to such incidents among colleagues and the lack of a clear policy and definitions to guide teachers in the classrooms and hallways were significant obstacles these teachers faced in their school cultures.

On the other hand, every single participant spoke of a personal commitment to challenging bias in the classroom. This was often paired with an articulation of a marginalized aspect of their own identity: woman, gay, or ethnic minority. Each of these teachers had a political consciousness about social inequalities that had been shaped by their own education and

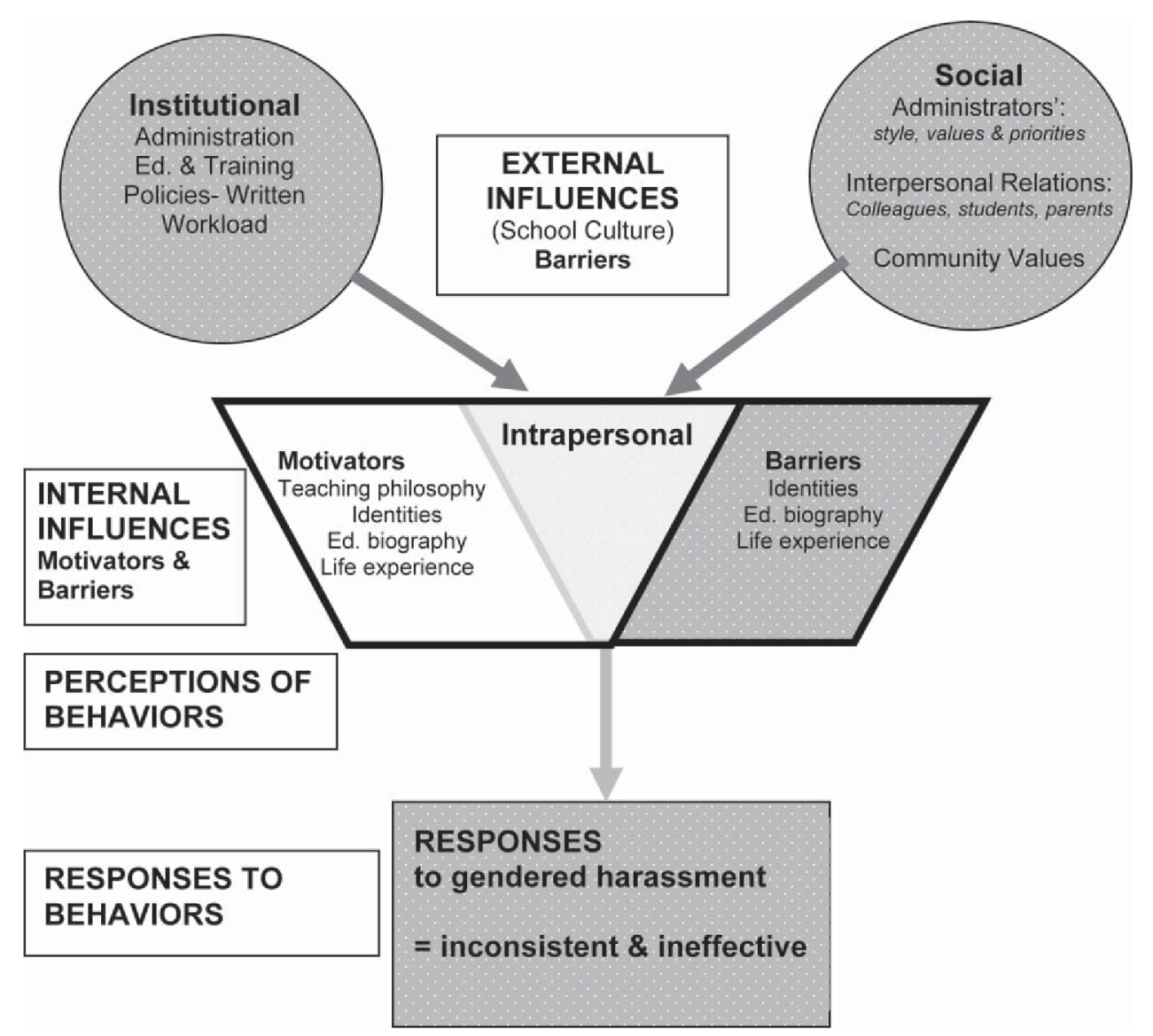

Figure 2. The coffee filter model: factors influencing teachers' (non) interventions.

personal experiences. This consciousness influenced their teaching philosophy and how they perceived their students and school cultures. They were articulate in critiquing issues with the social structure of the school and the impacts of other cultural factors that influenced students' experiences in their schools.

The findings in this research offer us a deeper understanding of how various forms of bullying and harassment are perceived and acted on by teachers in secondary schools. These data offer scholars, educators, and school leaders a clearer picture of some of the 
challenges that exist when trying to confront such forms of harassment between students in schools. Through the process of listening to teachers talk about their experiences with gendered harassment in secondary schools it is clear that it is not possible to create safer and more positive learning environments until school leaders initiate a whole-school process that engages students, families, teachers and community members in a process of transforming the formal and informal structures of the school.

\section{Note}

1. I have used the teachers' pseudonyms here for a reason. I hope it will help the reader connect with each teacher's identities and experiences, but will prevent direct connections between the teacher's identities, statements, and the school community in which they work and live.

\section{References}

Bem, S. 1993. The lenses of gender: Transforming the debate on sexual inequality. New Haven, CT: Yale University Press.

Bochenek, M., and A.W. Brown. 2001. Hatred in the hallways: Violence and discrimination against lesbian, gay, bisexual, and transgender students in US schools. New York: Human Rights Watch. Butler, J. 1990. Gender trouble. New York: RoutledgeFalmer.

California Safe Schools Coalition. 2004. Consequences of harassment based on actual or perceived sexual orientation and gender non-conformity and steps for making schools safer. Davis: University of California.

Chambers, D., E. Tincknell, and J. van Loon. 2004. Peer regulation of teenage sexual identities. Gender and Education 16, no. 3: 397-415.

Chambers, D., J. van Loon, and E. Tincknell. 2004. Teachers' views of teenage sexual morality. British Journal of Sociology of Education 25, no. 5: 563-76.

Connell, R.W. 1995. Masculinities. Sydney: Allen and Unwin.

Corbett, K., C.A. Gentry, and W.J. Pearson. 1993. Sexual harassment in high school. Youth \& Society 25, no. 1: 93-103.

DiGiulio, R.C. 2001. Educate, medicate, or litigate? Thousand Oaks, CA: Corwin Press.

Duncan, N. 1999. Sexual bullying: Gender conflict and pupil culture in secondary schools. London: Routledge.

- 2004. It's important to be nice, but it's nicer to be important: Girls, popularity and sexual competition. Sex Education 4, no. 2: 137-52.

Epstein, D., and R. Johnson. 1998. Schooling sexualities. Buckingham: Open University Press.

Friend, R. 1993. Choices, not closets: Heterosexism and homophobia in schools. In Beyond silenced voices: Class, race, and gender in United States schools, ed. L. Weis and M. Fine, 209-35. Albany: State University of New York Press.

Gay Lesbian and Straight Education Network (GLSEN) and Harris Interactive. 2005. From teasing to torment: School climate in America, a survey of students and teachers. New York: GLSEN.

Harris Interactive. 2001. Hostile hallways: Bullying, teasing, and sexual harassment in school. Washington, DC: American Association of University Women Educational Foundation.

Hepburn, A. 1997. Teachers and secondary school bullying - a postmodern discourse analysis. Discourse \& Society 8, no. 1: 27-48.

Jagose, A. 1996. Queer theory: An introduction. New York: New York University Press.

Jennings, R., and I. McGillivray. 2007. A content analysis exploring queer topics in foundations of education textbooks. Paper presented at the annual meeting of the American Educational Research Association, 9-13 April, in Chicago, IL.

Jones, G.H. 2005. Site-based voices: Dilemmas of educators who engage in activism against studentto-student sexual harassment. Paper presented at the annual meeting of the American Educational Research Association, 11-15 April, in Montreal, QC.

Kehler, M., K.G. Davison, and B. Frank. 2005. Contradictions and tensions in the practice of masculinities in school: Interrogating embodiment and "good buddy talk". Journal of Curriculum Theorizing Winter: 59-72.

Kosciw, J., and E. Diaz. 2006. The 2005 National School Climate Survey: The experiences of lesbian, gay, bisexual and transgender youth in our nation's schools. New York: Gay, Lesbian, and Straight Education Network.

Larkin, J. 1994. Walking through walls: The sexual harassment of high school girls. Gender and Education 6, no. 3: 263-80.

Lee, V., R.G. Croninger, E. Linn, and Z. Chen. 1996. The culture of sexual harassment in secondary schools. American Educational Research Journal 33, no. 2: 383-417.

Louis Harris and Associates. 1993. Hostile hallways: The AAUW survey on sexual harassment in America's schools. Washington, DC: American Association of University Women. 
Mac an Ghaill, M. 1995. The making of men: Masculinities, sexualities, and schooling. Philadelphia: Open University Press.

Maehr, M., and R. Buck. 1993. Transforming school culture. In Education leadership and school culture, ed. M. Sashkin and H.J. Wahlberg, 40-57. Berkeley, CA: McCutchan Publishing.

Martino, W. 1995. "Cool boys", "party animals", "squids" and "poofters": Interrogating the dynamics and politics of adolescent masculinities in school. British Journal of Sociology of Education 22, no. 2: 239-63.

Maykut, P., and R. Morehouse. 1994. Beginning qualitative research: A philosophic and practical guide. Philadelphia: Routledge.

Meyer, E.J. 2006. Gendered harassment in North America: School-based interventions for reducing homophobia and heterosexism. In Combating gender violence in and around schools, ed. C. Mitchell and F. Leach, 43-50. Stoke-on-Trent: Trentham Books.

- 2008. A feminist reframing of bullying and harassment: Transforming schools through critical pedagogy. McGill Journal of Education 43, no. 1: 33-48.

Mills, M. 2001. Challenging violence in schools: An issue of masculinities. Buckingham: Open University Press.

O'Conor, A. 1995. Who gets called queer in school? Lesbian, gay, and bisexual teenagers, homophobia, and high school. In The gay teen: Educational practice and theory for lesbian, gay, and bisexual adolescents, ed. G. Unks, 95-104. New York: Routledge.

Patton, M.Q. 2002. Qualitative research and evaluation methods. Thousand Oaks, CA: Sage. Poteat,

V.P., M. Eads, and M. Kimmel. 2006. Aggression and victimization in association with gender and gender-nonconforming behavior among adolescents. Washington, DC: Gender Public Advocacy Coalition.

Reed, C.A. 1996. Harassment policies: Structural limitations and hidden connections. Initiatives 58, no. 1: 21-26.

Reis, B. 1995. Safe schools anti-violence documentation project: Second annual report. Seattle, WA: Safe Schools Coalition of Washington.

Renold, E. 2000. "Coming out": Gender (hetero)sexuality and the primary school. Gender and Education 12, no. 3: 309-26.

Robinson, K.H. 2005. Reinforcing hegemonic masculinities through sexual harassment: Issues of identity, power and popularity in secondary schools. Gender and Education 17, no. 1: 19-37.

Robinson, K.H., and T. Ferfolja. 2001. "What are we doing this for?" Dealing with lesbian and gay issues in teacher education. British Journal of Sociology of Education 22, no. 1: 121-33.

Roscoe, B. 1994. Sexual harassment: Early adolescents' self-reports of experiences and acceptance. Adolescence 29, no. 115: 515-23.

Sears, J. 1991. Educators, homosexuality, and homosexual students: Are personal feelings related to professional beliefs? Journal of Homosexuality 22, nos. 3-4: 29-79.

Sedgwick, E.K. 1990/1993. Epistemology of the closet. In The lesbian and gay studies reader, ed. H. Abelove, M.A. Barale, and D.M. Halperin, 45-61. New York: Routledge.

Seidman, I. 1998. Interviewing as qualitative research: A guide for researchers in education and the social sciences. New York: Teacher's College Press.

Smith, G.W., and D. Smith, eds. 1998. The ideology of "fag": The school experience of gay students. Sociological Quarterly 39, no. 2: 309-35.

Stader, D., and T.J. Garca. 2006. Sexual minority youth and school culture: A study of educational leadership candidates' perceptions of Dallas-Fort Worth area secondary schools. Paper presented at the American Educational Research Association, 7-11 April, in San Francisco, CA.

Stein, N. 1992. Bitter lessons for all: Sexual harassment in schools. In Sexuality and the Curriculum, ed. J.T. Sears, 10-123. New York: Teachers College Press.

1995. Sexual harassment in school: The public performance of gendered violence. Harvard Educational Review 65, no. 2: 145-62.

Sullivan, N. 2003. A critical introduction to queer theory. New York: New York University Press. The Governor's Commission on Gay and Lesbian Youth. 1993. Making schools safe for gay and lesbian youth. No. 17296-60-500-2/93-C.R. Boston: The Commonwealth of Massachusetts.

Van Manen, M. 1997. Human science for an action sensitive pedagogy. Loudon, ON: Althouse Press.

Wilson, I., C. Griffin, and B. Wren. 2005. The interaction between young people with atypical gender identity organization and their peers. Journal of Health Psychology 10, no. 3: 307-15.

Wood, J. 1987. Groping towards sexism: Boys' sex talk. In Gender under scrutiny: New inquiries in education, ed. M. Arnot and G. Weiner, 187-230. London: Hutchinson Education. 